\title{
Research on Z-source Inverter Based on Harmonic Suppression
}

\section{Methods}

\author{
Haigang Zhang ${ }^{1, a}$, Yuanyuan $\mathrm{Nie}^{2, \mathrm{~b}}$, Yinzhong $\mathrm{Ye}^{3, \mathrm{c}}$, Bing $\mathrm{Xu}^{4, \mathrm{~d}}$, Weiwei $\mathrm{An}^{5, \mathrm{e}}$ \\ ${ }^{1}$ Shanghai Institute of Technology,Shanghai,China \\ aRimrim1@163.com, ${ }^{\mathrm{b} R} 1526300973 @ q q . c o m$
}

Keywords: Z-source inverter; harmonic analysis; THD

Abstract. Based on the $\mathrm{Z}$ source inverters operating characteristics studied, and has carried out harmonic analysis by simulation of its output voltage. Through the reasonable design of carrier frequency, filter design and triple frequency harmonic injection method to suppress the output voltage harmonic, the $\mathrm{Z}$ source inverter is simulated by SIMULINK. Through the analysis of the THD of output voltage, the method of $Z$ source inverter output voltage harmonic $s$ with good inhibitory effect.

\section{Introduction}

Due to the limitations of the traditional type and current-voltage inverter, they are either boost, or step-down, cannot be buck and boost inverter, which means the voltage range they get is limited. The presented of Z-source inverter[1]overcomes the shortcoming of traditional inverter and provides a good concept of power conversion. With the application of Z-source inverter, the suppression of output harmonic becomes increasingly important. In this paper, through the rational harmonic suppression method of Z-source inverter control, harmonically analyzing the output voltage to verify the correctness of suppression methods.

\section{The topology of the Z-source inverter}

Z-source inverter is between direct current voltage source of traditional inverter and the inverter switch plus an X-type network shown in Figure 1.Because of the addition of X-type impedance network can make the inverter bridge arm up and down at the same time conduction without burning, this is the booster mechanism of $\mathrm{Z}$ source inverter. X-type network consists of two equal values of inductance $\mathrm{L} 1, \mathrm{~L} 2$, and two equivalent capacitance values of $\mathrm{C} 1$ and $\mathrm{C} 2$.

$$
\left\{\begin{array}{l}
C_{1}=C=C_{2} \\
L_{1}=L=L_{2}
\end{array}\right.
$$

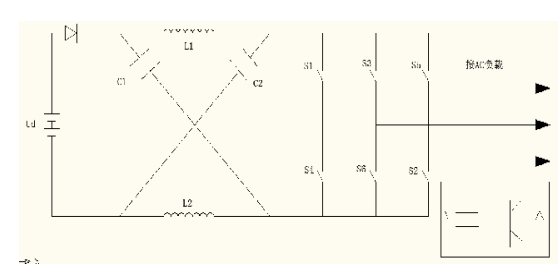

Fig.1: The topology of the Z-source inverter 


\section{The working principle of Z-source inverter}

Z-source network has two working models, one is the traditional model, the other is a pass-throughmode. Pass through mode is added straight zero vector in the traditional zero vectors, let the control signal of upper and lower leg is asymmetric, so as to achieve simultaneous conduction of state [2], which is the essence of Z-source inverter can boost. When Z-source network under the state of non-through, the equivalent circuit diagram shown in Figure 2.

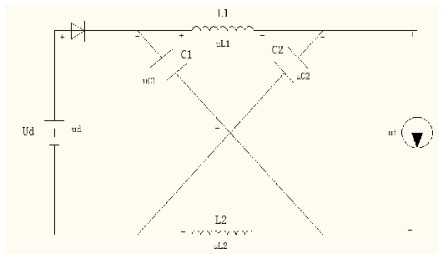

Fig.2: Non-straight state equivalent circuit

Assuming a switch cycle is $\mathrm{T}$, the time of Z-source inverter inthe state of traditional is $\mathrm{T} 1$, the straight time is $\mathrm{T} 0$, then

$$
\left\{\begin{array}{l}
U_{d}=U_{C 1}+U_{L 2} \\
U_{i}=U_{L 1}-U_{C 1}
\end{array}\right.
$$

Due to the symmetry of Z-source network,

$$
\left\{\begin{array}{l}
U_{C 1}=U_{C}=U_{C 2} \\
U_{L 1}=U_{L}=U_{L 2}
\end{array}\right.
$$

When the Z-source network working in the pass-through state, the equivalent circuit diagram is shown in Figure 3.

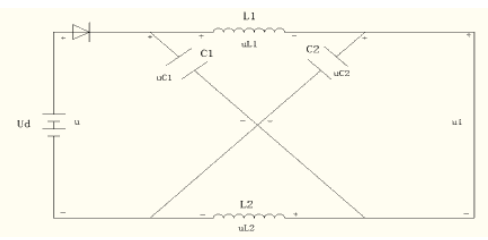

Fig.3: straight state equivalent circuit

$$
\left\{\begin{array}{c}
U_{d}=U_{C 1}+U_{C 2} \\
U_{i}=U_{L 1}-U_{C 1} \\
U_{i}=0
\end{array}\right.
$$

By Kirchhoff's law shows that the average voltage is 0 crossing the inductor in a switching period ends under steady-state conditions [3].

$$
\begin{gathered}
U_{L}=\left[T_{0} * U_{C}+T_{1} *\left(U_{d}-U_{C}\right)\right] 1 / T=0 \\
\frac{U_{C}}{U_{d}}=\frac{T_{1}}{T_{1-} T_{0}}=\frac{1-D}{1-2 D}=(1-D) * B
\end{gathered}
$$

\section{Z-source inverter output voltage harmonic analysis}

The harmonic analysis of the PWM waveform is very complicated, being specific to each the concrete position of the switch angles, so harmonic analysis to be carried out under certain circumstances. For convenience and accuracy of Z-source inverter output harmonic analysis, this article take the original dc power and the inverter switches are considered to be ideal, the pressure drop of the switching devices to the interference of output voltage. If considering the actual inverter 
switch dead zone, its analysis is quite complex, in this paper, the harmonic analysis of switch dead area influence is considered. Three $\mathrm{Z}$ source inverter line voltage waveform of the Fourier series expressions for

$$
\begin{aligned}
& U_{a b}=\frac{\sqrt{3}}{2} M B U_{d} \sin \left(\omega_{s} t-\frac{\pi}{3}\right)+\frac{4 U_{d} B}{m \pi} \sum_{m=1,2 L}^{\infty} \sum_{n= \pm 1, \pm 2}^{ \pm \infty} J_{n}\left(\frac{m M \pi}{2}\right) \\
& \sin \frac{(m N+n) \pi}{3} * \sin \left[(m N+n)\left(\omega_{s}-\frac{\pi}{3}\right)-\frac{n \pi}{2}\right]
\end{aligned}
$$

$\mathrm{M}$ is the modulation, $U_{d}$ is the DC voltage source, $f_{s}$ is the modulation wave frequency, $\mathrm{N}$ is the carrier ratio, $\mathrm{m}$ is the number of the carrier with respect to the harmonic, $\mathrm{n}$ is the harmonic frequency with respect to the modulation wave, $J_{n}$ is the first Bayesian function. The above equation output voltage harmonics that mainly concentrated in and around the vicinity of integer multiples of the carrier and the carrier wave modulation and frequency modulation wave frequency.

\section{Z-source inverter harmonic suppression strategy}

\section{The selecting of carrier ratio $\mathbf{N}$}

Since the fundamental wave of the inverter circuit output line phase voltage and the phase of the modulated wave is same, line voltage and the voltage is 30 difference, so the carrier ratio $\mathrm{N}$ should be an integer multiple of 3 [4], so ensures the symmetry of the output waveform . N is typically an odd number, to avoid even harmonics. $\mathrm{N}$ greater than the value of the carrier, the lowest harmonics will be farther away from the fundamental, it is a good filter, the output waveform is more accurate, and the corresponding reduction in harmonic content, but it will increase the switching frequency, increased switching losses. Therefore, a reasonable choice carrier ratio $\mathrm{N}$, to ensure the normal operation of the switch can also be reduced the harmonic output.

In the case of Z-source inverter other parameters are not changed, only change the carrier radio of $\mathrm{N}$, the output wave frequency is $50 \mathrm{~Hz}$, so the frequency modulation wave is also set to $50 \mathrm{~Hz}$. Figures 4, 5, 6 are $\mathrm{N}=900, \mathrm{~N}=1300$ and $\mathrm{N}=1800 \mathrm{FFT}$ analysis when $\mathrm{Z}$ source inverter output voltage waveform. Carrier ratio $\mathrm{N}$ can be drawn at an integer multiple of three, when total harmonic output voltage is less than the carrier ratio is not an integer multiple of 3 , the carrier ratio increases within a certain range, the smaller the amount of output voltage total harmonic.

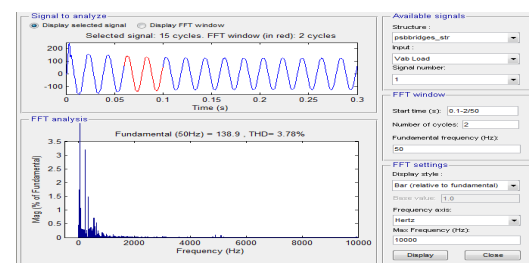

Fig.4: the output voltage of the FFT analysis when $\mathrm{N}=900$

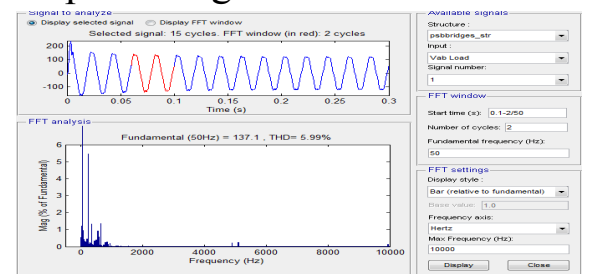

Fig.5: the output voltage of the FFT analysis when $\mathrm{N}=1300$ 


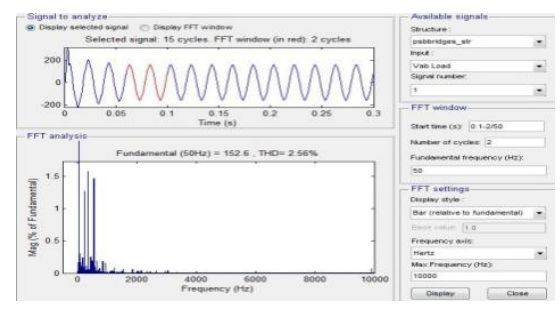

Fig.6: the output voltage of the FFT analysis when $\mathrm{N}=1800$

\section{The design of $\mathrm{LC}$ filter}

The theory and design methods of filter have been developed quite mature, and has many typical filter for us to choose, rationally design of passive filters (LC filters) can effectively reduce the harmonic output. In this paper, studying [5] Z-source inverter with the constant pressure method.The input DC voltage is $150 \mathrm{~V}$, selecting a passive filter by calculating the inductance $\mathrm{L}=$ 1e-3, the capacitance $\mathrm{C}=1 \mathrm{e}-4$.

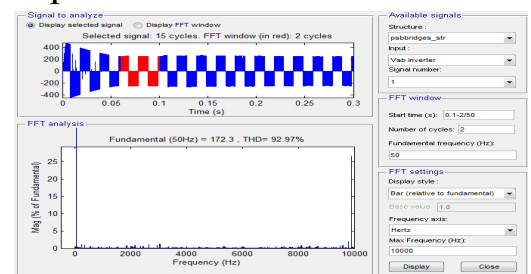

Fig.7: output voltage FFT analysis without filter

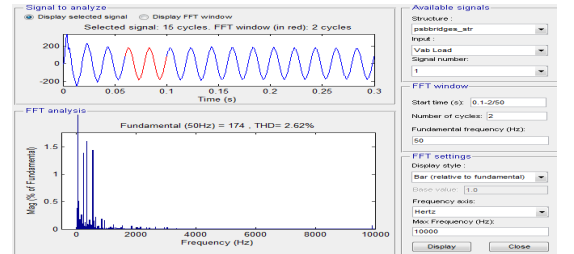

Fig.8: output voltage FFT analysis with filter

The total harmonic distortion of output voltage is up to $92.97 \%$ when not joined a passive LC filter,after adding a filter the THD is reduced to $2.62 \%$ which is in line with the requirements of the national total harmonic distortion of the grid, so the Z-source inverter plays a boost function.

\section{The addition method ofthird harmonic generation}

By adding the third harmonic generation of harmonics, in the case of guarantee the carrier ratio $\mathrm{N}$ is an integer multiple of 3 , increased the effective value of the output voltage, increased the power of output, improved performance of the inverter, and effectively restrain the harmonics. After adding three times frequency, its modulation wave function becomes

$$
S_{(\omega t)}=M \sin (\omega t)+a \sin (3 b \omega t)
$$

\section{Conclusions}

The simulation by Simulink to a different carrier than the next and before adding the filter simulation were compared, the result confirmed the Z-source inverter control strategy paper said harmonic reasonable carrier ratio and passive filter design good design can reduce the total harmonic distortion of the output.

Acknowledgements

The work is supported by The National Natural Science Foundation of China (Grant No. 61374132).

\section{References}

[1]Peng.F.Z.Z-Source Inverter[J]. IEEE Transactions on Industry Application, 2003,39(2):504-501. [2]Y. Tang, S. J. Xie, C. H. Zhang, Improved Z-source inverter with reduced Z-source capacitor 
voltage stress and soft-start capability, IEEE Trans. on Power Electronics. 2009, 24(1).

[3]KROPOSKI B,LASSETER R H,ISE T,et al.Makingmicrogrids work. Power and Energy Magazine .2008

[4]Bull S R.Renewable energy today and tomorrow. Proceeding of Tricomm.2001

[5] Peng F Z.Z-source inverter. IEEE Transactions on Industry Applications . 2003

[6] Fang Zheng Peng.Z-source inverter. Industry Applications, IEEE Transactions on . 2003

[7]LASSETER R H.Microgrids and distributed generation. Journal of Energy.2007

[8] Fan Zhang,Fangzheng Peng,Zhaoming Qian."Z-H Converter". Peanut Science . 2008

[9] F.Z.Peng."Z-Source Inverter,". Proc. of Industry Applications Conference . 2002

[10Baoming, GeQin, LeiWei Qi. A Family of Z-source Matrix Converters.IEEE Transaction on Industrial Electronic. 2012 